\title{
Risk factors for maternal mortality associated with eclampsia presenting at a Nigerian tertiary hospital
}

This article was published in the following Dove Press journal:

International Journal of Women's Health

\author{
Kabiru Afolarin Rabiu' \\ Adeniyi Abiodun \\ Adewunmi' \\ Tawakwalit Abimbola \\ Ottun' \\ Fatimat Motunrayo \\ Akinlusi' $^{\prime}$ \\ Adewunmi Adeoye \\ Adebanjo ${ }^{2}$ \\ Taiwo Ganiyat Alausa ${ }^{2}$ \\ 'Department of Obstetrics and \\ Gynaecology, Lagos State University \\ College of Medicine, Ikeja, Lagos \\ State, Nigeria; ${ }^{2}$ Department of \\ Obstetrics and Gynaecology, Lagos \\ State University Teaching Hospital, \\ Ikeja, Lagos State, Nigeria
}

\begin{abstract}
Background: Eclampsia remains a leading contributor to maternal mortality, particularly in developing countries, and remains a challenge even to the most experienced obstetrician. We aimed to determine the factors associated with maternal mortality in eclamptics at the Lagos State University Teaching Hospital (LASUTH), Nigeria, in order to suggest ways to prevent this avoidable tragedy.

Materials and methods: Data were prospectively collected with the aid of a specially designed proforma from January 1, 2011 to December 31, 2012. Comparison was made between the patients who died (cases) and the survivors (control). Univariate and multivariate analyses were carried out using logistic regression.

Results: The case fatality rate was $19.4 \%$. Factors independently associated with mortality were as follows: period between onset of seizures to arrival in LASUTH $>12$ hours (adjusted $\mathrm{OR}=22.04 ; 95 \% \mathrm{CI}=4.62-104.95 ; P=0.001$ ), vaginal delivery (adjusted $\mathrm{OR}=10.96$; 95\% CI=2.54-47.27; $P=0.0013$ ), presence of aspiration pneumonitis (adjusted $\mathrm{OR}=7.77$; 95\% CI $=2.37-25.46 ; P=0.0007$ ), and presence of renal failure (adjusted $\mathrm{OR}=7.09 ; 95 \%$ $\mathrm{CI}=2.14-23.48 ; P=0.0014)$. The use of magnesium sulfate reduced the risk of mortality (adjusted $\mathrm{OR}=0.25 ; 95 \% \mathrm{CI}=0.09-0.72 ; P=0.0104)$.

Conclusion: Maternal mortality in patients with eclampsia was associated largely with preventable factors. The use of standard obstetric services, prompt referral of patients for definitive care, and the use of simplified dosing regimen of magnesium sulfate may improve its utilization and also improve maternal outcome.
\end{abstract}

Keywords: maternal mortality, eclampsia, Nigeria

\section{Introduction}

Eclampsia remains the leading contributor to maternal mortality, particularly in developing countries accounting for death of about 50,000 women annually. ${ }^{1}$

The condition is relatively rare in developed countries because of the wider availability and utilization of modern obstetric care services. The incidence in the UK is about 2.7 per 10,000 deliveries, and an incidence of 1 in 3,704 was reported from Nova Scotia, Canada. ${ }^{2,3}$ The reported incidence in developing countries varies widely from about 1 in 12 to 1 in 1,700 deliveries. $^{4-7}$

In most developed countries, mortality associated with eclampsia has been reduced to the barest minimum. In the UK, no death was recorded in eclamptics managed between February 2005 and February 2006. ${ }^{2}$ In contrast, mortality from eclampsia is still very high in developing countries.

Recent reports emanating from Nigeria implicate eclampsia as the leading cause of maternal mortality contributing to $31.9 \%-46.4 \%$ of maternal deaths. ${ }^{8-10}$ This study was therefore undertaken to analyze the factors associated with maternal mortality
Correspondence: Kabiru Afolarin Rabiu Department of Obstetrics and Gynaecology, Lagos State University College of Medicine, I-5 Oba Akinjobi Way, G.R.A., Ikeja P.M.B. 21266, Lagos State, Nigeria

Tel +2348023036430

Email derabs@hotmail.com 
due to eclampsia in a series of hospitalized patients at the maternity unit of Lagos State University Teaching Hospital (LASUTH) and to suggest ways of preventing this avoidable tragedy.

\section{Materials and methods}

This was a prospective study conducted at the maternity unit of LASUTH, Ikeja, Lagos State, Nigeria, over a 2-year period, from January 1, 2011 to December 31, 2012. The LASUTH research and ethics committee gave approval for the study.

The hospital is one of the two tertiary hospitals with maternity services in metropolitan Lagos with a population of about 15 million inhabitants. The hospital accepts referrals from private clinics, maternity/nursing homes, traditional birth attendants, and other government hospitals.

On admission, the purpose of the study is explained to the accompanying relative or the patient if fully conscious. After verbal informed consent (as approved by the LASUTH research ethics committee) is obtained, a detailed history is taken from the patient's attendant with a reference to the referral letter where available and a thorough clinical examination is done. A bedside test for proteinuria is then done from a catheter specimen of urine. Blood sample is obtained for investigations, such as a full blood count, platelet count, coagulation profile, renal function tests, and liver function tests. Initial resuscitation and stabilization are done in the emergency room before transfer to the labor ward.

Magnesium sulfate is the drug of choice for the control and often prevention of seizures. The Zuspan regimen (ie, a stat dose of magnesium sulfate $4 \mathrm{~g}$ in a $10 \%$ or $20 \%$ solution as slow intravenous injection is given followed by infusion of magnesium sulfate regulated to deliver $1 \mathrm{~g}$ per hour) is used and monitoring is done by checking the deep tendon reflexes, urinary output, and respiratory rate. This infusion is discontinued if there is oliguria or anuria, respiratory depression, or absent deep tendon reflexes. Also, when magnesium sulfate is not available, as is the case sometimes, diazepam is used for the control of seizures. Hydralazine is commonly used as rapidly acting intravenous antihypertensive. It is given in a dose of $5 \mathrm{mg}$, and this is repeated after 20-30 minutes if the diastolic blood pressure is $\geq 110 \mathrm{mmHg}$. The aim is to keep the diastolic blood pressure between 90 and $100 \mathrm{mmHg}$.

After stabilization, the mode of delivery of these women before the onset of labor depends on the favorability of the cervix. If there is no contraindication to vaginal delivery, women with a Bishop score of 6 and above are offered amniotomy followed by induction of labor with oxytocin or misoprostol. Those with an unfavorable cervix are offered cesarean section. Women in labor are closely monitored with the aid of a partograph and labor augmented with oxytocin if there is slow progress. Cesarean section is performed for the usual indications such as failure to progress, cephalopelvic disproportion not likely to be solvable with an instrumental delivery or even after a failed instrumental delivery, and fetal distress. The second stage of labor is usually shortened with the aid of the ventouse or obstetrics forceps. The patients were then subsequently followed up till discharge from the hospital.

The cause of death was determined from the clinical history (postmortem examination is not routinely done in our center due to relatives' nonconsent). All the data were collected on a specially designed proforma. Confidentiality was maintained throughout the study by not including the patient's names in the proforma. A comparison was made between the patients who died (cases) and the survivors (control). Data collected were entered into the computer and analyzed using the Epi Info 3.5.3 statistical software of the Centers for Disease Control and Prevention, Atlanta, USA.

Data were analyzed using logistic regression. Crude odds ratio (cOR) and 95\% CIs for possible risk factors for mortality among eclamptics were calculated using univariate analysis. Only risk factors with a $P$-value $<0.05$ were fed into a multiple logistic regression model to obtain adjusted odds ratio (aOR) and determine independent contributors to maternal mortality.

\section{Results}

There were 7,558 deliveries during the study period and 211 patients had eclampsia, giving an institutional incidence of $2.8 \%$. Forty-one of the 211 eclamptics died, giving a case fatality rate of $19.4 \%$. These 41 deaths accounted for $28.7 \%$ of the 143 maternal deaths in our unit during the study period.

Table 1 shows that there was no significant difference between cases and controls with respect to sociodemographic characteristics. There was also no significant difference between cases and controls with respect to obstetrics characteristics as shown in Table 2.

The comparison of the cases and controls with respect to clinical presentation and management is depicted in Table 3. Multiple episodes of seizures $>2(\mathrm{cOR}=4.64 ; 95 \%$ $\mathrm{CI}=2.03-10.3 ; P=0.0003)$, presence of coma (cOR=2.64; $95 \% \mathrm{CI}=1.28-5.43 ; P=0.0085$ ), duration of onset of seizures to arrival in LASUTH $>12$ hours $(\mathrm{cOR}=17.19 ; 95 \%$ $\mathrm{CI}=6.80-43.44 ; P \leq 0.0001$ ), and vaginal delivery compared 
Table I Demographic characteristics of eclamptic women who died (cases) and survivors (controls)

\begin{tabular}{|c|c|c|c|c|c|}
\hline Characteristics & Cases, $n=4 \mid(\%)$ & Controls, $n=\mid 70$ (\%) & cOR & $95 \% \mathrm{Cl}$ & $P$-value \\
\hline \multicolumn{6}{|l|}{ Age, years } \\
\hline $14-19$ & $2(4.9)$ & $8(4.7)$ & 1.00 & Reference & \\
\hline $20-34$ & $24(58.5)$ & $122(7 \mid .8)$ & 0.79 & $0.17-3.94$ & 0.7705 \\
\hline$\geq 35$ & $15(36.6)$ & $40(23.5)$ & 1.37 & $0.26-7.21$ & 0.7134 \\
\hline \multicolumn{6}{|l|}{ Educational level } \\
\hline None & $22(53.7)$ & $83(48.8)$ & 1.00 & Reference & \\
\hline Primary & $12(29.3)$ & $39(22.9)$ & 1.16 & $0.52-2.58$ & 0.7174 \\
\hline Secondary & $4(9.8)$ & $24(14.1)$ & 0.63 & $0.20-2.00$ & 0.4323 \\
\hline Tertiary & $3(7.3)$ & $24(14.1)$ & 0.47 & $0 .|3-| .7 \mid$ & 0.2531 \\
\hline \multicolumn{6}{|l|}{ Occupation } \\
\hline Skilled & $3(7.3)$ & $21(12.4)$ & 0.79 & $0.21-3.00$ & 0.7287 \\
\hline Semiskilled & $15(36.6)$ & $83(48.8)$ & 1.00 & Reference & \\
\hline Unskilled & $3(7.3)$ & $21(12.4)$ & 0.79 & $0.21-2.99$ & 0.7287 \\
\hline Unemployed & $20(48.8)$ & $45(26.5)$ & 2.46 & $1.15-5.27$ & 0.0505 \\
\hline \multicolumn{6}{|l|}{ Marital status } \\
\hline Married & $37(90.2)$ & 155 (9I.2) & 1.00 & Reference & \\
\hline Single & $4(9.8)$ & $15(8.8)$ & 1.12 & $0.35-3.56$ & 0.8515 \\
\hline \multicolumn{6}{|l|}{ Religion } \\
\hline Christianity & $30(73.2)$ & $122(7 \mid .8)$ & 1.00 & Reference & \\
\hline Islam & $10(24.4)$ & $42(24.7)$ & 0.97 & $0.44-2.15$ & 0.9368 \\
\hline Others & I (2.44) & $6(3.5)$ & 0.68 & $0.08-5.84$ & 0.7234 \\
\hline
\end{tabular}

Abbreviation: cOR, crude odds ratio.

with cesarean section $(\mathrm{cOR}=2.55 ; 95 \% \mathrm{CI}=1.11-5.87$; $P=0.0272$ ) were found to be significant factors related to mortality. The use of magnesium sulfate was found to be related to a reduced risk of mortality when compared with the use of diazepam ( $\mathrm{cOR}=0.79 ; 95 \% \mathrm{CI}=0.18-0.71 ; P=0.0036$ ). The duration from admission to LASUTH to delivery did not significantly influence mortality in the patients.

Complications arising from eclampsia were seen in 153 $(72.5 \%)$ patients. Table 4 shows the comparison of cases and controls with respect to the presence of complications. Aspiration pneumonitis $(\mathrm{cOR}=4.82 ; 95 \% \mathrm{CI}=2.03-10.63$; $P=0.0036)$, acute renal failure $(\mathrm{cOR}=12.78 ; 95 \%$
$\mathrm{CI}=5.61-29.15 ; P \leq 0.0001)$, orofacial injury $(\mathrm{cOR}=2.80$; 95\% CI $=0.35-5.47 ; P=0.0054)$, disseminated intravascular coagulopathy (cOR=17.29; 95\% CI=3.34-86.84; $P=0.0005)$, and severe abnormal liver function $(\mathrm{cOR}=3.11 ; 95 \%$ $\mathrm{CI}=1.24-7.81 ; P=0.0155)$ were all found to be significant risk factors for mortality on univariate analysis.

After entering the significant factors in the univariate analysis into a multiple logistic regression model for multivariate analysis (Table 5), more than two episodes of convulsion, presence of coma, orofacial injury, disseminated intravascular coagulopathy, and severe abnormal liver function were no longer significant factors for mortality. The factors

Table 2 Obstetric characteristics of eclamptic women who died (cases) and survivors (controls)

\begin{tabular}{|c|c|c|c|c|c|}
\hline Characteristics & Cases, $n=4 \mid$ (\%) & Controls, $\mathbf{n}=\mathbf{I 0}(\%)$ & cOR & $95 \% \mathrm{Cl}$ & $P$-value \\
\hline \multicolumn{6}{|l|}{ Parity } \\
\hline 0 & $26(63.4)$ & $95(55.9)$ & 1.00 & Reference & \\
\hline $1-4$ & $14(34.1)$ & $69(40.6)$ & 0.74 & $0.36-1.52$ & 0.4152 \\
\hline$\geq 5$ & I (2.4) & $6(3.5)$ & 0.61 & $0.07-5.28$ & 0.6528 \\
\hline \multirow{2}{*}{\multicolumn{6}{|c|}{$\begin{array}{l}\text { Gestational age } \\
\text { at delivery, weeks }\end{array}$}} \\
\hline & & & & & \\
\hline$<28$ & I (2.4) & $5(2.9)$ & 1.00 & Reference & \\
\hline $28-37$ & $16(39.0)$ & $74(43.5)$ & 1.08 & $0.08-0.12$ & 0.9450 \\
\hline$\geq 38$ & $2(58.5)$ & 91 (53.5) & 1.34 & $1.32-1.47$ & 0.8084 \\
\hline \multicolumn{6}{|l|}{ Type of eclampsia } \\
\hline Antepartum & $7(17.1)$ & $42(24.7)$ & 1.00 & Reference & \\
\hline Intrapartum & $32(78.0)$ & $103(60.6)$ & 1.86 & $0.76-4.55$ & 0.1717 \\
\hline Postpartum & $2(4.9)$ & $25(14.7)$ & 0.48 & $0.09-2.50$ & 0.3825 \\
\hline
\end{tabular}

Abbreviation: cOR, crude odds ratio. 
Table 3 Clinical presentation and management of eclamptic women who died (cases) and survivors (controls)

\begin{tabular}{|c|c|c|c|c|c|}
\hline Characteristics & Cases, $n=4 I(\%)$ & Controls, $n=170(\%)$ & cOR & $95 \% \mathrm{Cl}$ & $P$-value \\
\hline \multicolumn{6}{|l|}{ Number of seizures } \\
\hline$<3$ & $8(19.5)$ & $90(52.9)$ & 1.00 & Reference & \\
\hline$\geq 3$ & $33(80.5)$ & $80(47.1)$ & 4.64 & $2.03-10.63$ & 0.0003 \\
\hline \multicolumn{6}{|l|}{ Presence of coma } \\
\hline Yes & $17(53.7)$ & $36(2 \mid .2)$ & 2.64 & $1.28-5.43$ & 0.0085 \\
\hline No & $24(58.5)$ & $134(78.8)$ & 1.00 & Reference & \\
\hline \multicolumn{6}{|c|}{$\begin{array}{l}\text { Duration of onset seizures to } \\
\text { arrival in LASUTH (in hours) }\end{array}$} \\
\hline$<7$ & $13(3 \mid .7)$ & $117(68.8)$ & 1.00 & Reference & \\
\hline $7-12$ & $7(17.1)$ & $43(24.7)$ & 1.50 & $0.56-4.01$ & 0.4194 \\
\hline$>12$ & $21(51.2)$ & II (6.5) & 17.19 & $6.80-43.44$ & $<0.0001$ \\
\hline \multicolumn{6}{|c|}{ Use of magnesium sulfate } \\
\hline Yes & $20(48.8)$ & $124(72.9)$ & 0.79 & $0.18-0.71$ & 0.0036 \\
\hline No & $21(51.2)$ & $46(27.1)$ & 1.00 & Reference & \\
\hline \multicolumn{6}{|l|}{ Mode of delivery } \\
\hline Vaginal & $33(80.5)$ & $105(61.8)$ & 2.55 & I.II-5.87 & 0.0272 \\
\hline Cesarean section & $8(19.5)$ & $65(38.2)$ & 1.00 & Reference & \\
\hline \multicolumn{6}{|c|}{$\begin{array}{l}\text { Duration from admission to } \\
\text { delivery in LASUTH (in hours) }\end{array}$} \\
\hline$\leq 6$ & $32(82.1)$ & II 5 (79.3) & 1.00 & Reference & \\
\hline$>6-12$ & $6(15.4)$ & $24(16.6)$ & 0.90 & $0.34-2.39$ & 0.8398 \\
\hline$>12$ & I (2.6) & $6(4.1)$ & 0.60 & $0.07-5.15$ & 0.6406 \\
\hline
\end{tabular}

Abbreviations: cOR, crude odds ratio; LASUTH, Lagos State University Teaching Hospital.

Table 4 Presence of complications in eclamptic women who died (cases) and survivors (controls)

\begin{tabular}{|c|c|c|c|c|c|}
\hline Characteristics & Cases, $n=4 \mid(\%)$ & Controls, $n=170$ (\%) & cOR & $95 \% \mathrm{Cl}$ & $P$-value \\
\hline $\begin{array}{l}\text { Aspiration pneumonitis } \\
\text { Yes } \\
\text { No }\end{array}$ & $\begin{array}{l}26(63.4) \\
15(36.6)\end{array}$ & $\begin{array}{l}45(26.5) \\
125(73.5)\end{array}$ & $\begin{array}{l}4.82 \\
1.00\end{array}$ & $\begin{array}{l}2.03-10.63 \\
\text { Reference }\end{array}$ & 0.0036 \\
\hline $\begin{array}{l}\text { Renal failure (oliguria/anuria or } \\
\text { abnormal renal function tests) }\end{array}$ & & & & & $<0.000$ I \\
\hline $\begin{array}{l}\text { Yes } \\
\text { No }\end{array}$ & $\begin{array}{l}32(78.0) \\
9(22.0)\end{array}$ & $\begin{array}{l}37(2 \mid .8) \\
\mid 33(78.2)\end{array}$ & $\begin{array}{l}12.78 \\
1.00\end{array}$ & $\begin{array}{l}5.61-29.15 \\
\text { Reference }\end{array}$ & \\
\hline Orofacial injury & & & & & 0.0054 \\
\hline Yes & $28(68.3)$ & $74(43.5)$ & 2.80 & $0.35-5.47$ & \\
\hline No & $13(31.7)$ & $96(56.5)$ & 1.00 & Reference & \\
\hline $\begin{array}{l}\text { Abruptio placentae } \\
\text { Yes } \\
\text { No }\end{array}$ & $\begin{array}{l}3(7.3) \\
38(92.7)\end{array}$ & $\begin{array}{l}9(5.3) \\
|6|(94.7)\end{array}$ & $\begin{array}{l}1.41 \\
1.00\end{array}$ & $\begin{array}{l}0.36-5.7 \\
\text { Reference }\end{array}$ & 0.6172 \\
\hline $\begin{array}{l}\text { Disseminated intravascular coagulopathy } \\
\text { Yes } \\
\text { No }\end{array}$ & $\begin{array}{l}7(17.1) \\
34(82.9)\end{array}$ & $\begin{array}{l}2(1.2) \\
168(98.8)\end{array}$ & $\begin{array}{l}17.29 \\
1.00\end{array}$ & $\begin{array}{l}\text { 3.34-86.84 } \\
\text { Reference }\end{array}$ & 0.0005 \\
\hline $\begin{array}{l}\text { Cerebral edema } \\
\text { Yes } \\
\text { No }\end{array}$ & $\begin{array}{l}3(7.3) \\
38(92.7)\end{array}$ & $\begin{array}{l}4(2.4) \\
166(97.6)\end{array}$ & $\begin{array}{l}3.28 \\
1.00\end{array}$ & $\begin{array}{l}0.70-15.35 \\
\text { Reference }\end{array}$ & 0.1304 \\
\hline $\begin{array}{l}\text { Pulmonary edema } \\
\text { Yes } \\
\text { No }\end{array}$ & $\begin{array}{l}2(4.9) \\
39(95.1)\end{array}$ & $\begin{array}{l}2(1.2) \\
168(98.8)\end{array}$ & $\begin{array}{l}4.31 \\
1.00\end{array}$ & $\begin{array}{l}0.59-31.54 \\
\text { Reference }\end{array}$ & 0.1505 \\
\hline $\begin{array}{l}\text { Severe abnormal liver function } \\
\text { Yes } \\
\text { No }\end{array}$ & $\begin{array}{l}9(22.0) \\
32(78.0)\end{array}$ & $\begin{array}{l}14(8.3) \\
155(91.7)\end{array}$ & $\begin{array}{l}3.11 \\
1.00\end{array}$ & $\begin{array}{l}|.24-7.8| \\
\text { Reference }\end{array}$ & 0.0155 \\
\hline
\end{tabular}

Abbreviation: cOR, crude odds ratio. 
Table 5 Multivariate logistic regression analysis of significant factors predicting independent risk factors for mortality in eclamptics

\begin{tabular}{l|l|l|l}
\hline Factors & aOR & $\mathbf{9 5 \% ~ C l}$ & $\mathbf{P}$-value \\
\hline Number of seizures $\geq 3$ & 3.54 & $0.98-12.83$ & 0.0541 \\
Presence of coma & 1.26 & $0.36-4.42$ & 0.7086 \\
$\begin{array}{l}\text { Onset of seizures to arrival } \\
\text { in LASUTH }>\text { I2 hours }\end{array}$ & 22.04 & $4.62-104.95$ & $0.000 \mathrm{I}$ \\
Vaginal delivery & 10.96 & $2.54-47.27$ & 0.0013 \\
Use of magnesium sulfate & 0.25 & $0.09-0.72$ & 0.0104 \\
Aspiration pneumonitis & 7.77 & $2.37-25.46$ & 0.0007 \\
Renal failure & 7.09 & $2.14-23.48$ & 0.0014 \\
Orofacial injury & 1.23 & $0.41-3.73$ & 0.7149 \\
Disseminated intravascular & 1.65 & $0.18-15.18$ & 0.6562 \\
coagulation & & & \\
Abnormal liver function & 1.0 & $0.17-5.89$ & 0.9994 \\
\hline
\end{tabular}

Abbreviations: aOR, adjusted odds ratio; LASUTH, Lagos State University Teaching Hospital.

that remained significant were period between onset of convulsion to arrival in LASUTH $>12$ hours $(\mathrm{aOR}=22.04 ; 95 \%$ $\mathrm{CI}=4.46-104.95 ; P=0.001)$, vaginal delivery $(\mathrm{aOR}=10.96$; 95\% CI $=2.54-47.27 ; P=0.0013$ ), aspiration pneumonitis (aOR=7.77; 95\% CI=2.37-25.46; $P=0.0007)$, and acute renal failure $(\mathrm{aOR}=7.09 ; 95 \% \mathrm{CI}=2.14-23.48 ; P=0.0014)$. The use of magnesium sulfate reduced the risk of mortality $(\mathrm{aOR}=0.25 ; 95 \% \mathrm{CI}=0.09-0.72 ; P=0.0014)$.

\section{Discussion}

Eclampsia continues to account for significant maternal and perinatal morbidity and mortality and remains a challenge even to the most experienced obstetricians especially in the developing countries. This study highlights a number of preventable and practical issues that influence mortality in patients presenting with eclampsia at a Nigerian tertiary hospital.

The incidence of eclampsia (2.8\%) in this study is higher than the prevalence of $0.91 \%$ recently reported from the Nnamdi Azikiwe University Teaching Hospital, Nnewi, South East Nigeria, ${ }^{6}$ but similar to $2.3 \%$ reported from the Baptist Medical Center, Delta state, Nigeria, ${ }^{11}$ and 2.52\% reported at the Irrua Specialist Hospital, Edo state, Nigeria. ${ }^{12}$ This incidence is much higher than that reported from the developed countries. An incidence of $0.027 \%$ was reported from all 229 consultant-led maternity units in the UK, ${ }^{2}$ while an incidence of $0.056 \%$ was recently reported from the Abha Maternity Hospital, Saudi Arabia. ${ }^{7}$ A much higher rate of 9\% was however reported from the Dhaka Medical College and Hospital, Bangladesh. ${ }^{4}$

The case fatality rate of $19.4 \%$ recorded in this study is similar to recent reports from other parts of Nigeria. Olatunji and Sule Odu reported a case fatality rate of $20 \%$ from Sagamu in western Nigeria, ${ }^{13}$ while Kullima et al reported a case fatality rate of $22.3 \%$ from Nguru in northern Nigeria. ${ }^{14}$ A lower mortality rate of $14.7 \%$ was reported from Dhaka in Senegal,${ }^{15}$ while a case fatality rate of $6.7 \%$ was reported from a study of 342 cases of eclampsia in Morocco. ${ }^{16}$ Maternal death rates from eclampsia are much lower in the developed countries probably because of their well-developed healthcare systems. No maternal deaths were reported in recent reports from the $\mathrm{UK}^{2}$ and Saudi Arabia. ${ }^{7}$

It is pertinent to note that eclampsia was the leading cause of maternal mortality in our institution during the study period accounting for $28.7 \%$ of the 143 maternal deaths. Recent reports from other institutions in the country also reported eclampsia as the leading cause of maternal deaths. ${ }^{8-10}$

Maternal mortality in eclamptics in this study was found to be associated mainly with avoidable factors. Majority of the patients were referred from other health facilities that apparently lacked the capacity to manage eclampsia and many of them presented late for management. This late presentation could be due to either delay in seeking care or delay in referral for definitive care. This study showed that arrival at our hospital 12 hours or more after the onset of seizures increased the risk of maternal death about 22-fold. Previous studies have reported adverse outcomes associated with delay in referral of eclamptics. Tukur et al in his review in Kano, Nigeria, found that delay before hospital presentation was significantly associated with mortality in eclamptics. ${ }^{17}$ Hussain in Dhaka, Senegal, also reported that mortality was higher in eclamptics admitted $>5$ hours after the onset of seizures. ${ }^{15}$

In Nigeria, superstition and traditional beliefs may also be responsible for the delay in transfer of women to health facilities. Many associate problems in pregnancy with witchcraft and the supernatural and therefore present first to churches, faith healing centers, and the traditional healer and then only present to the hospital as a last resort when complications have already set in. Financial constraints may also be responsible for the delay in presenting to definitive care after referral. The role of the poor state of the roads, suboptimal transportation facilities, and nonavailability of ambulance services in late presentation to health facilities can also not be overemphasized.

Various studies have associated the presence of complications with mortality in eclamptics. The majority of the patients had complications associated with eclampsia. 
Aspiration pneumonitis and acute renal failure were the commonest complications associated with mortality in eclampsia in this study, and they increased the risk of mortality almost eight-fold and seven-fold, respectively. Acute renal failure and aspiration pneumonitis are welldocumented complications of eclampsia and have been reported to be associated with mortality in these patients. It is therefore imperative that these complications are carefully searched for at presentation and when present, immediate treatment measures instituted. When these complications have not set in, immediate stabilization and prompt delivery are advised as delay in delivery may lead to complications and worsened prognosis.

The definitive treatment for eclampsia is delivery. Once the maternal conditions have been stabilized, delivery should be expedited. However, there appears to be no consensus on the best mode of delivery. While some previous studies in Nigeria gave the impression that cesarean section in eclamptics was associated with higher risk of mortality when compared with vaginal delivery, ${ }^{18,19}$ this study showed that vaginal delivery increased the risk of mortality almost elevenfold when compared with cesarean section. This may be due to the fact that much more time was lost between first fit and delivery and suggests the need for early recourse to cesarean section in these patients and not as a last resort when prolonged attempts at vaginal delivery have failed. Our finding is similar to that reported from Enugu in eastern Nigeria ${ }^{20}$ and also the report by Khosla et al in Haryana, India. ${ }^{21}$ Olatunji and Sule Odu however did not find any significant difference in mortality between eclamptics delivered vaginally and those delivered by cesarean section. ${ }^{13}$

Based on the available evidence, the World Health Organization has recommended magnesium sulfate as the most effective, safe, and low-cost drug for the treatment of severe pre-eclampsia and eclampsia, and it has been the standard treatment in developed countries for over 20 years. ${ }^{22}$ Unfortunately, less effective drugs such as diazepam and phenytoin are still used sometimes in most developing countries, and most low-resource countries do not have guidelines mandating the use of magnesium sulfate. ${ }^{22}$ At the obstetrics unit of the LASUTH, magnesium sulfate is the drug of choice, but the drug is sometimes not available and diazepam has to be administered in these cases. This study showed that the use of magnesium sulfate significantly reduced the risk of mortality from eclampsia when compared with the use of diazepam. This finding is similar to some reports from other parts of Nigeria where magnesium sulfate is not universally used. ${ }^{17,23}$
The noncompliance with the strict use of magnesium sulfate in most developing countries can be partly attributed to the current regimens for magnesium sulfate requiring complicated dilution and delivery techniques and also the initially thought narrow safety margin and the perceived need for close monitoring of the patients in the face of shortage of skilled medical personnel. ${ }^{22,23}$ It has however been reported that magnesium sulfate toxicity is not as common and that clinical monitoring of women is sufficient. ${ }^{24}$ Also in Nigeria, many of the health facilities do not have the drug in stock. It was therefore not surprising that only three out of 10 maternity units of tertiary hospitals that were visited for postgraduate medical accreditation in 2009 had magnesium sulfate in the emergency trays of their labor rooms. In contrast, diazepam ampoules were on the emergency trays at all sites, indicating that diazepam may be the drug that is used in case of emergency. ${ }^{25}$

Recent researches have suggested that a simplified dosing regimen may improve compliance with magnesium sulfate use in resource-poor settings. Some studies have demonstrated the effectiveness of using a loading dose-only regimen to treat patients with eclampsia. ${ }^{26,27}$ This reduces the complexity of dosing and decreases the risk of toxicity because most cases of magnesium sulfate toxicity are related to the administration of maintenance doses. This may be particularly beneficial in resource-poor countries that lack the staff, equipment, and medications to safely monitor and treat magnesium sulfate toxicity.

Another promising intervention is the suggestion that magnesium sulfate may be administered as a rectal suppository in patients with pre-eclampsia and eclampsia. ${ }^{28}$ This has the potential to simplify dosing, provide a less painful method for delivery compared with existing delivery methods, and allow use at the lower levels of the continuum of care by reducing the need for highly skilled healthcare providers and is therefore worth further investigation especially in resource-poor settings like Nigeria.

In conclusion, this study shows that the factors associated with mortality in patients with eclampsia are largely preventable and include late presentation after the onset of convulsions, presence of aspiration pneumonitis or acute renal failure, vaginal delivery instead of cesarean section, and the nonuse of magnesium sulfate. Urgent interventions are required. A major emphasis should be placed on education to emphasize the importance of good antenatal care and prompt referral of patients for definitive care. Magnesium sulfate should be subsidized or made free to patients as is done for antiretroviral drugs by the government and 
developmental partners. The simplified loading dose-only regimen may improve the utilization of magnesium sulfate, and the rectal use of the drug is worth further investigations in resource-poor countries based on the advantages it could have over existing delivery methods.

\section{Disclosure}

The authors report no conflicts of interest in this work.

\section{References}

1. World Health Organization. International Collaborative Study of Hypertensive Disorders of Pregnancy. Geographic variations in the incidence of hypertension in pregnancy. Am J Obstet Gynecol. 1998;151: $80-83$.

2. Knight M. Eclampsia in the United Kingdom 2005. BJOG. 2007;114(9): 1072-1078.

3. Lee W, O'Connell CM, Baskett TF. Maternal and perinatal outcomes of eclampsia: Nova Scotia, 1981-2000. J Obstet Gynaecol Can. 2004; 26(2):119-123.

4. Begum MR, Begum A, Quadir E, Akhter S, Shamsuddin L. Eclampsia: still a problem in Bangladesh. Med Gen Med. 2004;6(4):52.

5. Adam GK, Bakheit KH, Adam I. Maternal and perinatal outcomes of eclampsia in Gagarif Hospital Sudan. J Obstet Gynaecol. 2007;27: $150-154$.

6. Adinma ED. Maternal and perinatal outcome of eclampsia in tertiary health institution in Southeast Nigeria. J Matern Fetal Neonatal Med. 2013;26(2):211-214.

7. Sobande AA, Eskandar M, Bahar A, Abusham A. Severe pre-eclampsia and eclampsia in Abha, the south west region of Saudi Arabia. J Obstet Gynaecol. 2007;27(2):150-154.

8. Mairiga AG, Saleh W. Maternal mortality at the State Specialist Hospital Bauchi, Northern Nigeria. East Afr Med J. 2009;86(1):25-30.

9. Tukur J, Jido TA, Awolaja BS. Maternal mortality in rural northern Nigeria. Trop Doct. 2008;38(1):35-36.

10. Kullima AA, Kawuwa MB, Audu BM, Geidam AD, Mairiga AG. Trends in maternal mortality in a tertiary institution in Northern Nigeria. Ann Afr Med. 2009;8(4):221-224.

11. Igberase GO, Ebeigbe PN. Eclampsia: ten-years of experience in a rural tertiary hospital in the Niger delta, Nigeria. J Obstet Gynaecol. 2006; 26(5):414-417.

12. Okogbenin SA, Eigbefoh JO, Omorogbe F, Okogbo F, Okonta PI, Ohihoin AG. Eclampsia in Irrua Specialist Teaching Hospital: a fiveyear review. Niger J Clin Pract. 2010;13(2):149-153.
13. Olatunji AO, Sule Odu AO. Maternal mortality from eclampsia. JObstet Gynaecol. 2006;26(6):542-543.

14. Kullima AA, Kawuwa MB, Audu BM, Usman H, Geidam AD. A 5-year review of maternal mortality associated with eclampsia in a tertiary institution in northern Nigeria. Ann Afr Med. 2009;8(2):81-84.

15. Hussain F, Johanson RB, Jones P. One year survey of maternal mortality associated with eclampsia in Dhaka Medical College Hospital. J Obstet Gynaecol. 2000;20(3):239-241.

16. Miguil M, Chekairi A. Eclampsia, study of 342 cases. Hypertens Pregnancy. 2008;27(2):103-111.

17. Tukur J, Muhammad Z. Management of eclampsia at AKTH: before and after magnesium sulphate. Niger J Med. 2010;19(1):104-107.

18. Itam IH, Ekabua JE. A review of pregnancy outcome in women with eclampsia at the University of Calabar Teaching Hospital, Calabar. Trop J Obstet Gynaecol. 2001;18(2):66-68.

19. Odum CU, Ijioma I. A critical evaluation of the influence of caesarean delivery on the final outcome in eclampsia in Lagos University Teaching Hospital (LUTH). Nig J Med. 1992;2:196-202.

20. Onah HE, Okaro JM. Caesarean section in the delivery of Nigerian eclamptics. Trop J Obstet Gynaecol. 2001;18(1):34-37.

21. Khosla AH, Dahiya K, Sangwan K. Maternal mortality in eclampsia: 489 cases. Trop Doct. 2006;36(1):47-49.

22. Langer A, Villar J, Tell K, Kim T, Kennedy S. Reducing eclampsiarelated deaths - a call to action. Lancet. 2008;371(9614):705-706.

23. Eke AC, Ezebialu IU, Okafor C. Presentation and outcome of eclampsia at a tertiary center in South East Nigeria - a 6-year review. Hypertens Pregnancy. 2011;30(2):125-132.

24. Ekele BA, Badung SL. Is serum magnesium estimate necessary in patients with eclampsia on magnesium sulphate? Afr J Reprod Health. 2005; 9(1):128-132.

25. Ekele BA. Use of magnesium sulfate to manage pre-eclampsia and eclampsia in Nigeria: overcoming the odds. Ann Afr Med. 2009;8(2): 73-75.

26. Begum MR, Begum A, Quadir E. Loading dose versus standard regime of magnesium sulfate in the management of eclampsia: a randomized trial. J Obstet Gynaecol Res. 2002;28(3):154-159.

27. Shoaib T, Khan S, Javed I, Bhutta SZ. Loading dose of magnesium sulphate versus standard regime for prophylaxis of pre-eclampsia. J Coll Physicians Surg Pak. 2009;19(1):30-33.

28. Rectal Delivery of magnesium sulfate: Simplifying Anticonvulsant Therapy for Severe Preeclampsia/Eclampsia. Available from: https:// www.path.org/resources/rectal-delivery-of-magnesium-sulfate-simplifying-anticonvulsant-therapy-for-severe-preeclampsiaeclampsia/. Accessed January 24, 2018.
International Journal of Women's Health

\section{Publish your work in this journal}

The International Journal of Women's Health is an international, peerreviewed open-access journal publishing original research, reports, editorials, reviews and commentaries on all aspects of women's healthcare including gynecology, obstetrics, and breast cancer. The manuscript management system is completely online and includes

\section{Dovepress}

a very quick and fair peer-review system, which is all easy to use. Visit http://www.dovepress.com/testimonials.php to read real quotes from published authors. 